\title{
RIVAC Regimen
}

National Cancer Institute

\section{Source}

National Cancer Institute. RIVAC Regimen. NCI Thesaurus. Code C153313.

A regimen consisting of rituximab, ifosfamide, cytarabine and etoposide that can be used in the treatment of non-Hodgkin lymphoma (NHL). 